FOUNDATIONS

\title{
OF INDUCTIVE LOGIC
}


By the same author

INTERNATIONAL ECONOMICS

THE TRADE CYCLE. AN ESSAY

BRITAIN'S FUTURE POPULATION

A PAGE OF BRITISH FOLLY

ARE THESE HARDSHIPS NECESSARY?

TOWARDS A DYNAMIC ECONOMICS

THE LIFE OF JOHN MAYNARD KEYNES

AND SO IT GOES ON

ECONOMIC ESSAYS

THE DOLLAR

POLICY AGAINST INFLATION

THE PROF. A PERSONAL MEMOIR OF LORD CHERWELL

TOPICAL COMMENT

THE BRITISH ECONOMY

REFORMING THE WORLD'S MONEY

TOWARDS A NEW ECONOMIC POLICY

DOLLAR-STERLING COLLABORATION

MONEY

SOCIOLOGY, MORALS AND MYSTERY

ECONOMIC DYNAMICS 


\title{
FOUNDATIONS \\ $\mathrm{OF}$ \\ INDUCTIVE LOGIC
}

\author{
B Y \\ ROY HARROD
}

MACMILLAN EDUCATION 
This book is copyright in all countries which are signatories to the Berne Convention

Softcover reprint of the hardcover 1st edition 1974 978-0-333-16951-3

All rights reserved. No part of this publication may be reproduced or transmitted, in any form or by any means, without permission.

First edition 1956

Reissued with a new preface 1974

Published by

THE MACMILLAN PRESS LTD

London and Basingstoke Associated companies in New York

Dublin Melbourne Fohannesburg and Madras

SBN 333 I695I 4

ISBN 978-1-349-02329-5 ISBN 978-1-349-02327-1 (eBook)

DOI 10.1007/978-1-349-02327-1

This reissue published in the United States 1974

by Rowman and Littlefield, Totowa, N.J. 


\section{CONTENTS}

Preface to the Reissue

PAGE

Preface to the First Edition

vii

ix CHAP.

I INTRODUCTORY I

II Probability 24

III The Principle of Experience 49

IV INVERSE PROBability

V NatURal Kinds 120

VI Simplicity $\quad 146$

VII Truth, Belief and KNowledge 159

$\begin{array}{ll}\text { VIII MEMORY } & 184\end{array}$

IX Ontological Digression 201

X Fundamental Principles of Induction 240

XI BEYOND EXPERIENCE 262

$\begin{array}{ll}\text { INDEX } & \mathbf{2 8 7}\end{array}$ 


\section{PREFACE TO THE REISSUE}

IT IS a pleasure to me that there should be a republication of my book on inductive logic. Of my works, it is the one of which I am most proud, but it is by no means the best known.

In the contribution to my Festschrift that he was good enough to make, Sir Alfred Ayer writes 'Sir Roy Harrod's book on the Foundations of Inductive Logic has not attracted the attention which it deserves. A great deal has been written on this subject since 1956, when Harrod's book was published, but I have found very few references to it in the literature and hardly any serious attempt to evaluate its conclusions. Yet there is no doubt that if these conclusions are sound, they are, as Harrod claims, of great philosophical importance. For reasons which I shall give, I do not think that he does make his main contention good, but his argument is highly ingenious, and his fidelity to the empiricist standpoint, which I share with him, is admirably consistent. Even if his claim to have solved one of the most intractable problems of philosophy is not acceptable, it calls for serious attention.'

One could hardly have a greater tribute from one who, while a foremost philosopher of his generation, is a complete sceptic.

Scepticism has its appeal, and perhaps a greater appeal than most philosophies, yet, if it were indeed the case that the process of reasoning from experience were invalid, it would be a curious coincidence, with odds against of many billions of billions of billions to one, that we should have that understanding of the processes of nature that lets us get along with our daily lives.

January 1974

R.F.H. 


\section{PREFACE TO THE FIRST EDITION}

APOLOGY is due from one who, with few credentials, comes forward and claims to make a major contribution in a difficult subject. I have acute and painful feelings of diffidence in the presence of learned colleagues in the academic field, including men of great distinction who have devoted their whole lives to philosophy. I console myself with this thought: it is commonly agreed that in philosophy the prime method of research is neither the study of the printed word nor the conduct of experiments, but reflexion. To the subjects dealt with in this volume I have devoted concentrated and arduous reflexion for numerous periods in the last twenty years; and they have been of interest to me over a longer stretch of time. I am well acquainted with all the agonies of frustration when, again and again, hopeful lines of approach have to be abandoned. I have not failed to pay in arduous toil what may be deemed a proper price for venturing to publish my conclusions.

I should not be frank if I did not express the belief that these conclusions are of great importance. Only that belief could give me face with myself in being so bold as to publish, although a layman in the field. On my first introduction to philosophy I appreciated that the theory of induction was in an unsatisfactory condition. Nineteenth-century attempts to vindicate it had been discredited. During my lifetime the hope of doing so has been largely abandoned. Distinguished philosophers have lapsed into feeble forms of pragmatism. Some have sought refuge from the uncomfortable sense of failure in this field in a comforting dogma, which claims not only that induction cannot be vindicated, but that any attempt to vindicate it would entail some kind of self-contradiction. Yet it is on the face of it strange that there should be no means of vindicating on general principles those methods of thought that have led man forward to so many intellectual triumphs. I claim to be setting out in this volume, 
although only in the roughest outline and without finish, what the essential principles of induction are, and to show that these principles are co-equal in validity and authority and certainty with the principles of deduction.

In the past it has been thought that the validity of induction depended on the prior acceptance of such principles as the Law of Universal Causation and the Uniformity of Nature. More recently it has been claimed that we have to assume initial prior probabilities for certain beliefs. All such prior postulates have been totally dispensed with here. If induction is to be vindicated, it must be vindicated without any prior assumptions about the nature of the universe whatever. In this I subject myself to Hume, the great master. Starting from his basic principles I have, I would claim, rebutted his sceptical conclusions. Indeed one way of characterizing this volume would be as the refutation of Hume. My hope is that no future Keynes, reviewing the progress of inductive theory, may be able to say 'Hitherto Hume has been the master, only to be refuted in the manner of Diogenes or Dr. Johnson'.

Being concerned with induction, this book is also necessarily a treatise on probability. This has been the subject of fully developed mathematical theory. It is clear that the doctrines that I have set out should be given mathematical expression. I lack the qualifications to do this, but believe that this is not fatal to my work, which, to use an old-fashioned word, may be regarded as the prolegomena to the theory of probability. It would naturally be a source of pride if it inspired a mathematical treatment and development of its central concepts. I would only add one ungracious word of warning. I have the impression that there is a rather considerable gulf between the logical faculty and the purely mathematical faculty. This may have tended to be obscured by recent developments of symbolic logic, which are of the first importance in their own way. The mathematician is largely concerned with the manipulation of symbols. His quality does not of course show itself merely in the correctness of his manipulation, but in his genius in discerning how to devise, by a use of symbols, a correct movement of thought from one point to another : for example, in finding the proof of a given theorem. The symbols constitute a safeguard. 
Logicians, perhaps inspired by mathematics, have believed it their task to set up a system of symbols and of rules for their use which would provide similar safeguards in proving logical theorems. This has become prominent in symbolic logic, but the tendency dates from Aristotle's syllogism. Misconceptions are involved here ; the proper task of logic is to criticize and interpret any set of symbols or rules, and, when that criticism and interpretation have been achieved, the task of logic proper ends. Thus 'symbolic logic' should only be an appendix to logic proper.

Logic is concerned with the relation known as 'entailment'. It has been traditionally divided into deductive logic and inductive logic. There has recently been some tendency to claim that any considerations concerning entailment belong to deductive logic ; this leaves the status of inductive logic, considered as a normative discipline, somewhat obscure. It will be contended in this volume that deduction and induction are co-equal branches of the general theory of entailment.

If the doctrines here set out are correct, much, perhaps most, current thought about induction is wrong. The theory of induction should take on a new lease of life. If this is true, it can hardly be denied to be of some philosophical importance. I would even venture further. In madern times philosophy has become very specialized, and the thoughtful members of the community have felt less qualified to take an interest in it than they did in the nineteenth century. This may be inevitable, but it is unfortunate. Although people of this type now feel somewhat cut off from the details of the subject, they are yet aware that at the very heart of modern philosophy there is an extreme degree of scepticism. In this way treatises that are fully understood only by a handful may yet have a very wide influence, and I have the idea that this influence may be harmful and discouraging to strong resolve and high determination in relation to human progress. The great belief in progress of the nineteenth century is often derided, but there is a sense in which we still live on the capital created by that belief; the great movements of amelioration which are yielding ever more abundant fruits to-day had their original impetus in nineteenth-century hopefulness. That hopefulness was not unconnected with a certain self-confidence among 
philosophers. We now see flaws in their reasoning, which lie at the very basis of their thought. Twentieth-century philosophers, aware of those flaws, appear to have capitulated. We are not now creating a new capital of hopefulness. It is my conviction that the surrender and the resort to the easy paths of pragmatism or scepticism have been made too readily. The problems involved are difficult, but to judge them insoluble is a sign of complacency. For these reasons I claim, although I am aware that this is almost painfully presumptuous, that a reconstruction of inductive logic is not only of professional philosophical interest, but of wide-reaching importance for the good of society.

It is usual in a preface to provide a list of acknowledgements. Owing to the peculiar circumstances of my case, perhaps I may be forgiven for a brief resumé which is more biographical than bibliographical in character. In boyhood my great debt was to J. S. Mill, always to be relied on to kindle enthusiasm in the adolescent mind. I also became acquainted with some of the work of Bertrand Russell, and went to Oxford full of a brimming enthusiasm to learn what modern thought could rescue from Mill, and to get a deeper understanding of the exciting developments initiated by Russell. My hopes were utterly disappointed. I found in Oxford no one who was interested in the things that had interested me, no one even who seemed to have the faintest comprehension of why such things could possibly interest anyone. The prevailing school of philosophy at that time, based ultimately on the thought of the Ancients, had been given a special twist by Professor J. Cook-Wilson and perhaps could be described as a kind of common-sense realism. And there was a minority school which still derived inspiration from Kant and belonged to the tradition of T. H. Green and Bradley. These preoccupations, however, were consistent with an instruction to pupils to read, in addition to the Ancients, the original texts of Locke, Berkeley and Hume, and that was a great gain. I remain unrepentant in the view that this group of British philosophers has not been matched by any other, ancient or modern. But in general the Oxford experience was one of complete frustration. The arguments that seemed good and valid in Oxford struck me as invalid, and the arguments I sought to bring forward struck 
my mentors as invalid. But my mentors were far more skilled in argument than $\mathrm{I}$; and the result of the whole experience was total discouragement.

I add by way of digression that the Oxford philosophical scene has since changed out of recognition, and good foreign judges have informed me that Oxford now stands high in world regard for the vitality of its philosophical thinking. A notable contribution to the transition was made by Professor H. H. Price who, while much influenced by the Cook-Wilson school, developed independent and important lines of thinking of his own. In early days we had philosophical walks together, until he outpaced me, physically as well as mentally. A larger change was made some ten years later when Professor Ayer appeared on the scene. Bringing to the task a fiery zeal, masterly lucidity of exposition, dialectic skill, lightning riposte, and philosophical quality of the highest order, he made a devastating onslaught on established positions. He showed great moral courage. Examiners took his deviation to be due merely to lack of intellectual capacity. But when he came into open debate and entered into controversy without restraint, they had to take him a little more seriously, and were displeased. So strong was the hold of orthodoxy that he would not have received academic appointment in Oxford but for a series of happy accidents. But he had sown the seed; younger men listened, and his disciples were soon established in teaching positions. The Oxford philosophical scene had been transformed. In this connexion it is proper to record that his tutor, who was Professor Gilbert Ryle, had already, albeit by slower steps, proceeded far from the old Oxford orthodoxy towards those positions which he has since made famous by his writing.

To return to the main narrative, my own profound philosophical disappointment ten years earlier was relieved by some faint rays of hope. I had known the Whitehead family from schoolboy days ; I often visited them until Alfred Whitehead's departure for Harvard, and found in many talks with him a support for the view that I might not be altogether wrong in my discontent with Oxford philosophy. In 1922 I went to Cambridge for a period in quest of economic wisdom. There I found among the undergraduates Frank Ramsey, Professor 
R. A. Braithwaite and Mr. J. S. Bentwich, with whom I had enlightening talks. Ramsey's prestige was already great owing to the high esteem in which Bertrand Russell and Keynes were known to hold him, and the interest he showed in his delightfully easy style of philosophical conversation gave me further moral support. We maintained an occasional interchange of visits until his premature and tragic death. During the 'twenties, I had many long sessions of discussion with Lord Cherwell, largely in the early hours of the morning. His mind is wide-ranging and has great penetration wherever it chooses to alight on a subject of interest. Some parts of philosophy were comprehended in this interest, and here again I found support for the view that in my disagreement with Oxford orthodoxy I might not be altogether in the wrong.

During what I may call my fallow period in philosophy, the book that impressed me most was J. Nicod's Foundations of Geometry and Induction. The clarity and beauty of his thought, his power of selecting and concentrating upon central points of philosophic interest, and the remorselessness with which he pressed his reasoning to its logical conclusion, yet always against a background of tentativeness in relation to larger issues, have seemed to me to give him a rank in philosophy which it would be hard to match in the twentieth century. I came back to these essays after twenty-five years (but I had re-read the one on induction while engaged on writing the Life of Keynes), and was as delighted as before; and indeed $I$ had the feeling that his thought had been working in me at an unconscious level throughout the period. The essay on induction is slight ; he had the conviction, which he was not yet able to justify by explicit argument, that induction by simple enumeration was more fundamental than induction by methods of elimination. That is the standpoint of this volume.

At some time late in the 'thirties $I$ went to a meeting of an Oxford philosophical society to which G. E. Moore read a paper, either on the subject of, or anyhow mainly concerned with, memory. It was a characteristic production; he used his tremendous power of persuasion to recommend the view that we were talking the utmost nonsense if we put forward any doubt about whether our clear memories were true. 
Bertrand Russell was in the audience; in a few words he put forward a sensible and timely plea for scepticism; after all, we were sometimes deceived in what seemed to be very clear memories indeed. I do not know if he entertained more constructive views upon the subject of memory; if he did, he did not vouchsafe them on that occasion. I returned to my rooms, my brain on fire. Here I had just been listening to two men who might well be ranked as the two most distinguished philosophers of our time, and between them they had said on the central and all-important topic of the validity of memory nothing to the point at all. Yet trust in memory is necessary for almost all our thinking. There had been no hint whatever that we are entitled to trust memory simply because our general experience gives us inductive reasons for doing so. A strong inner voice said that it was intolerable to let the matter stand like that, and I resolved to give it my thought.

It very soon became evident that nothing could be done for memory unless one was standing on sure ground in holding induction to be valid. That brought one back to the old, old question. I wrestled with this problem for a long time, and, to my joy, was able to convince myself that the problem was soluble. During the early months of the late war I found an opportunity for setting out my views in the form of an article on memory. It appeared in Mind (January 1942), and I give the following extract from it :

'May it not be that the inductive hypothesis can be accepted a priori not merely as a working hypothesis but as a truth ? The proposition is that if certain things have been found to remain stable for some time, they are likely to continue to do so for a little longer. This proposition is conditional. It is not claimed that stable elements have been found, for the memory hypothesis is still subject to inquiry.

'It may be feared that I am endeavouring to reintroduce the principle of the uniformity of nature in new phraseology. But this is by no means so. I am only claiming a uniformity limited in space and time and scope of application, and I am only claiming probability, not certainty. The general 
uniformity of nature appears to me a wild and somewhat disreputable speculation of philosophers.

'The principle for which I argue can only be established by reference to the general nature of the universe. Of this in a certain sense we know nothing a priori. It might be a Heracleitean flux through and through, or it might be uniform through and through, or it might be any form of admixture. But suppose it were possible to discover by experience that it was not Heracleitean through and through, would anything follow? Let us suppose that by experience it was discovered to have certain stable elements in some part of it. Experience only vouches with certainty for that part of it which constitutes the experience. Accepting the experience and turning to review the general constitution of the universe, it would be possible to say of it that it has in a certain part of it stable elements. Now, if contact has been made with certain stable fragments, it is improbable at any time that one is on the extreme edge of those fragments. Whatever their size, it is much more probable that one is at some distance from the edge.

'To say that anything is as likely to happen as anything else at a given moment despite experience, is to affirm that immediately outside experience the universe is entirely Heracleitean. If it has not been so within experience, then one must just have finished exploring the whole of a specialised fragment, and this, though possible, is a priori improbable.

'The principle stated is related to the theory of sampling, and it is suggested that it should stand at the basis of all logic. Of course, as is well known, a sample may be entirely misleading; and this is recognised when it is admitted that the universe may at the next instant dissolve and leave not a wrack behind. In the absence of knowledge to the contrary the sample may be accepted as a guide to what is likely to be in the vicinity.

'It is important to emphasise that this principle is not based on experience ; only if its validity is independently established, shall we be able to tap the findings of past experience. Within a present, however, we have experience of one kind of continuity-spatial. In reflecting upon this, 
we may contemplate an example of an application of the principle. A room commonly contains smooth surfaces of various shapes and sizes. Suppose a man's vision, reduced to a pin-point, to move for a pre-determined finite length over a surface, or alternatively the finger of some one blindfolded. It is improbable that at the end of the time it would rest on the edge of the surface. This proposition is independent of the sizes of the objects and of the distribution of their sizes. There is no assumption of an equally probable chance of each size or of a distribution according to any law. The room may be filled with a chance collection of heterogeneous objects ; the probability is valid, however improbable-according to some other principle-is the distribution of sizes; and of course it is assumed that this is entirely unknown. The meaning of this probability principle may here be interpreted in terms of frequency. If a large number of experiments are made, the eye or hand will come to rest on the edge of a surface much less often than at some point a finite distance from the edge.

'It may be objected that the experiment will take time to perform. But no experiment is necessary. The truth may be apprehended $a$ priori within a given present. No doubt, if the experiment is made, the principle will be verified. But, as in the case of some more sophisticated probability propositions, the experiment would be entirely bogus ; if carried out, it would only serve to establish the propriety of the conditions, namely that the parties to it had acted in good faith, and not the truth of the probability proposition itself.

'There need be no hesitation in passing from spatial to temporal continuities, for the spatial character of the surface plays no part in aiding the mind to apprehend the probability law.'

Soon the facts of war wrapped us more tightly in their embrace, but I devoted all my spare time for a number of months to a resolve to master Quine's Mathematical Logic.

In the attempt to formulate the principle of probability implicit in the foregoing paragraphs, I realized that if one considered a multiplicity of occasions of being upon a surface, 


\section{xviii FOUNDATIONS OF INDUCTIVE LOGIC}

one would require some fair sampling postulate. It accordingly seemed that one needed to get a set of occasions within which a probability relation could be established from experience on a single surface. When I showed a rough draft to my learned colleague, Professor J. O. Urmson, he pointed out that my solution was unsatisfactory because in the estimate of probability at a particular point the judgements already made on the journey over the surface were past and done with and no longer relevant to an estimation of probability, and yet my estimate of probability had to include them within the class. In consideration of this difficulty, I came to apprehend the relation set out in the square diagram on page 56 . This constitutes the foundation of my theory; all else depends on and follows from it. It at once struck me that publication was desirable, and, after a lapse of some years, an article setting out the point appeared in Philosophy (January $195 \mathrm{I}) .^{\mathrm{I}}$

Once this central position was established, other doctrines fell into place fairly easily - the basic theory of simple enumeration, the possibility of dispensing with the fair sampling postulate, the justification of argument by analogy, of the single crucial experiment, and of the preference for simple over complex laws as scientific explanations. As a result of some discussion, Professor A. J. Ayer invited me to give five lectures to his class in London in the autumn of 1954. I there had the benefit of comments by himself and members of the staff.

In recent years, I have tried to enrich my knowledge by reading a number of treatises that have appeared recently, as well as the older classics. While I hope I have derived philosophic strength from such reading and have become acquainted with the current treatment of a wide range of problems, the main conclusions of this volume have been reached independently, and are the fruit of consecutive thinking for many years.

It was only when the main part of my task was finished that I read Professor Broad's well-known articles on induction and probability (Mind, 1918 and 1920). In the second of these

I I am afraid that my philosophy was at that time so rusty that I actually referred to the 'method of agreement' when I meant to refer to the 'method of simple enumeration'. 
he approaches positions that are very similar to mine. But he falters, and, in my judgement, falls into confusion. The result is inconclusive.

Still later certain references caused me to read Professor D. Williams's The Ground of Induction. I am in substantial agreement with that volume. There are many matters which he does not take up. His inductive system really depends upon a single point (explained on pages 93-104). But that point is correct and all important. Professor Williams appears to write as one who feels himself to be solus contra mundum. He alone in the present age believes that the validity of induction can be demonstrated without prior assumptions. I am in complete accord. It strikes me as painful and a bad symptom that his work has not already had a more widespread influence.

It remains to express gratitude to those who have given me direct assistance. First and foremost I must mention Professor H. H. Price, who read the greater part of my manuscript and took the trouble to write out a very extensive commentary, which has been of great value to me. Professor A. J. Ayer has continued to give me encouragement ; he also arranged for the course of lectures in University College, London, to which reference has already been made. Professor J. Sprott read certain sections; he gave me the benefit of his opinions and also the opportunity of ventilating mine in Nottingham. Mr. Handel Davies, my mathematical colleague in Christ Church, looked over those sections where the text touches on the fringe of mathematical problems and made some helpful criticisms. I must express my deep appreciation to Mr. O. P. Wood, also of Christ Church, who made time in the course of a busy term to study my galley sheets. While expressing no views about the validity of my arguments, on a number of points he made observations which were so pertinent that I felt impelled to alter my text in almost every passage on which they bore. Mr. John Sparrow, an unfailing source of sage advice on all literary questions, has read through this preface, except for this paragraph of it. I am grateful to my wife for helping in the laborious task of making an index.

Christ Church

R. F. H. June 1956 